\title{
Aspectos Punitivos do Tratamento nas Comunidades Terapêuticas: O Uso de Drogas como Dano Social
}

\author{
Punitive Aspects of Treatment in Therapeutic Communities: \\ The Use of Drugs as Social Damage
}

\section{Aspectos Punitivos del Tratamiento en las Comunidades Terapéuticas: El Uso de Drogas como Daño Social}

\author{
Luciana Barcellos Fossi ${ }^{1}$ \\ Universidade do Vale do Taquari
}

\author{
Neuza Maria de Fátima Guareschi
}

Universidade Federal do Rio Grande do Sul

\begin{abstract}
Resumo
Este artigo tem como objetivo discutir o caráter punitivo no tratamento para usuários de drogas em Comunidades Terapêuticas na região Sul do Brasil. Para isso analisamos os projetos terapêuticos dessas instituições que abordam a especificidade do tratamento de usuários de álcool e outras drogas pela vivência prescrita pelos doze passos. Tomando as concepções foucaultianas sobre poder psiquiátrico, disciplina e punição problematizamos o modo como essas instituições fundamentam e estruturam o modelo terapêutico sustentando-se numa lógica proibicionista a partir da moral do trabalho, da família e da religião. Apontamos, assim, as práticas punitivas no tratamento para usuários de drogas como uma biopolítica que compõem a política nacional no que tange aos cuidados de saúde no contexto das Comunidades Terapêuticas.
\end{abstract}

Palavras-chave: tratamento, punição, comunidade terapêutica

\begin{abstract}
This article has as goal argue the punitive treatment for drugs users in therapeutic community licensed under the Single Health System in Brazil's Southern region. For that analyzed the therapeutic projects of these institutions that treat the specificity of the treatment of young users of alcohol and other drugs by the experience prescribed by the twelve steps. Taking the conceptions Foucauldian of psychiatric power, discipline and punishment we problematize the way how these institutions justify and structure the therapeutic model of supporting itself in a prohibitionist logic based on morality of work and the family and institution religion values. We point this way the punitive practices in treatment for drugs users as a biopolitics that make up the health national policies in the context of in therapeutic community. Keywords: treatment, punishment, therapeutic community
\end{abstract}

\section{Resumen}

Este artículo tiene como objetivo discutir el carácter punitivo en el tratamiento para usuarios de drogas en Comunidades Terapéuticas en la región Sur de Brasil. Para ello analizamos los proyectos terapéuticos de esas instituciones que abordan la especificidad del tratamiento de usuarios de alcohol y otras drogas por la vivencia prescrita por los doce pasos. Tomando las concepciones foucaultianas sobre poder psiquiátrico, disciplina y castigo problematizamos el modo en que esas instituciones fundamentan y estructuran el modelo terapéutico sosteniéndose en una lógica prohibicionista a partir de la moral del trabajo, de la familia y de la religión. Por lo tanto, señalamos las prácticas punitivas en el tratamiento para usuarios de drogas como una biopolítica que componen la política nacional en lo que se refiere a la atención de salud en el contexto de las Comunidades Terapéuticas.

Palabras clave: tratamento, castigo, comunidad terapéutica

\footnotetext{
${ }^{1}$ Endereço de contato: Rua Pistoia 820/70, Canoas, RS. CEP 92200-290. Fone: (51) 99828-4040. E-mail: lubfossi@hotmail.com
} 


\section{Introdução}

A inserção das comunidades terapêuticas na rede pública de atenção à saúde no Brasil tem se apresentado como questão a ser problematizada no campo da Psicologia. A partir de 2010, o governo federal passou a investir fortemente na questão das drogas, propondo novas estratégias e reforçando outras já existentes, bem como incrementando o orçamento para as ações propostas a fim de solucionar o 'problema' ou, pelo menos, minimizá-lo. As comunidades terapêuticas, serviços de internação na modalidade de moradia para usuários drogas, passaram a compor a rede de saúde pública através do financiamento estatal.

Dentre os serviços previstos para usuários de substâncias psicoativas, as comunidades terapêuticas não faziam parte da rede de atenção à saúde, já que não eram consideradas serviços de saúde. As comunidades terapêuticas são instituições privadas e, muitas vezes, de caráter confessional, em que a religião é apresentada como estratégia de tratamento, independentemente das convicções religiosas do indivíduo anteriores ao ingresso nela. Elas possuem um programa específico de tratamento, que dura de seis a doze meses, conforme a instituição, regras rígidas e atividades obrigatórias, que devem ser seguidas por todos aqueles que ingressam na instituição. As visitas dos familiares são parcas e restritas e o contato com o mundo externo é inexistente, inclusive, no que diz respeito às atividades escolares e profissionais.

\section{A Lógica Proibicionista na Constituição das Políticas Públicas no Brasil}

Ao analisar o discurso do combate às drogas, Bucher e Oliveira (1994) destacam os mecanismos de poder envolvidos nesse discurso, mecanismos que indicam formas de disciplinarização diante de um contexto autoritário e repressivo, pois ele vem atrelado a um amplo projeto normalizador das relações sociais. Diante da ameaça de condutas desviantes, ". . . funda-se a prescrição normativa que desencadeia o controle, a intervenção e a exclusão" (Bucher \& Oliveira, 1994, p. 144). Os argumentos utilizados pelo discurso de combate às drogas, que impõem a manutenção da ordem moral, social e econômica vigente, dizem respeito às estruturas de poder e o sistema de normas dominantes. A norma, de acordo com Veiga-Neto (2007), é o elemento que individualiza, mas que, paralelamente, incide sobre o conjunto de indivíduos, permitindo a comparação entre eles. Com esta comparação, é possível designar como anormal aqueles cuja diferença em relação à maioria é excessiva, em que a diferença é considerada um desvio.

No ensejo do paradigma proibicionista deflagrado pela política global de guerra às drogas, conforme Delmanto e Magri (2011), a medicina construiu parâmetros que colocam a droga como causadora de dependência, que é entendida como doença. A ciência médica, articulada à proibição das drogas e ao poderio político-econômico da indústria farmacêutica, pretende a cura do que compreende como enfermidade, difundindo o ideário de uma sociedade medicalizada em sua totalidade. A política brasileira tem uma perspectiva, predominantemente, patologizadora do uso de drogas; se é doença, trata-se com remédio. Mas, para isso, é preciso que o usuário cesse o consumo de drogas para que ele possa ser tratado. É nesse ponto em que o discurso médico-biológico fortalece o tratamento nas comunidades terapêuticas, pautado pelo isolamento social e pela abstinência. De acordo com Alarcon (2012), o proibicionismo tem sua sustentação no duplo elo constituído entre o discurso sanitário, em sua busca "moralizada" de saúde, e o discurso criminológico. 
A política de segurança pública no Brasil segue a lógica do proibicionismo, seguindo o caminho oposto à tentativa de construção do SUS e da Reforma Psiquiátrica, em que o cuidado à saúde não deveria estar atravessado pela visão moralizante daqueles que usam drogas. A lógica do tratamento para usuários de drogas na política pública de saúde estaria pautado pela Redução de Danos, que não prioriza, necessariamente, a abstinência. Existe, portanto, um embate entre os gestores e trabalhadores da saúde, implicados com o cuidado na lógica da Redução de Danos e na defesa do SUS devido ao caráter proibicionista do tratamento que é adotado pelas comunidades terapêuticas.

A inserção da comunidade terapêutica na rede de cuidados está, diretamente, ligada à política de segurança já que é através de um edital da Secretaria Nacional de Políticas sobre Drogas (SENAD), vinculado ao Ministério da Justiça, que elas passaram a ser conveniadas. Contudo, estas comunidades terapêuticas, antes mesmo de seu conveniamento, já funcionavam contando com os saberes e as práticas das disciplinas "psi" aliados à lógica religiosa de moralização dos sujeitos.

De acordo com Passos e Souza (2011), o exercício de poder gerado no embate entre forças democráticas e forças totalitárias resultou em um jogo de contradições entre a Constituição Brasileira e o Código Penal: a primeira garantindo o direito a liberdades individuais e o segundo proibindo que os pessoas usem certas substâncias. Tal contradição remete à conciliação sinistra entre democracia e totalitarismo sobre o eixo das drogas.

Uma problematização necessária no âmbito das políticas públicas diz respeito ao fato de que tanto o Ministério da Saúde quanto o Ministério da Justiça incidem sobre a temática, mas, em princípio, em perspectivas diferentes. Se de um lado, o Ministério da Saúde indicava a Redução de Danos como diretriz para a política de álcool e outras drogas, por outro, o Ministério da Justiça, através da SENAD prioriza a internação, inclusive a de longa duração, em comunidades terapêuticas, em uma perspectiva de abstinência. No entanto, a verba que financia os leitos nas comunidades terapêuticas é advinda do Ministério da Saúde, que deveria legislar, justamente, no sentido oposto do que está colocado pela SENAD, por preconizar a Redução de Danos como diretriz para o tratamento. A partir do Decreto n. 7.179 (Brasil, 2010) e do edital de conveniamento das comunidades terapêuticas subsequente ao decreto, SENAD e Ministério da Saúde se articulam na operacionalização da política de drogas.

No final de 2011, através do plano "Crack, é possível vencer", o governo federal anunciou o investimento de R\$ 4 bilhões em ações para enfrentar o crack, prevendo a criação de mais 2.462 leitos para internação de usuários de drogas e a abertura de 2.500 vagas em comunidades terapêuticas. O plano contou, ainda, com uma capacitação intitulada "Fé na Recuperação", para lideranças religiosas através de curso promovido pela SENAD. Portanto, estabelece formalmente o papel das instituições religiosas na execução da política nacional proposta pela SENAD.

Com isso, faz-se importante compreender qual a proposta de tratamento das comunidades terapêuticas, sua estrutura e seu funcionamento, para que seja possível problematizar a inserção destas instituições como um serviço da rede pública de atenção aos usuários de substâncias psicoativas. 


\section{Estrutura e Funcionamento das Comunidades Terapêuticas}

A modalidade de tratamento em comunidade terapêutica surgiu na Grã-Bretanha na década de 1940. Inicialmente, foi utilizada para atenção a pessoas com problemas psiquiátricos crônicos a partir da experiência com militares que haviam retornado da guerra com problemas, predominantemente, psicológicos, que eram tratados por psiquiatras em alas especiais de hospitais gerais. O objetivo era que os pacientes doentes conhecessem melhor seu diagnóstico através de uma aprendizagem social resultante da interação entre profissionais e pacientes. Para isso, eram realizadas reuniões diárias com todo o grupo de pacientes internados e equipe responsável (Jones, 1972).

Muitas comunidades terapêuticas para tratamento de usuários de substâncias psicoativas seguem o modelo de tratamento preconizado pelo Alcoólicos Anônimos (AA). O AA surgiu em 1935 nos Estados Unidos e se caracteriza por ser uma organização composta, exclusivamente, por ex-bebedores. O método do AA está fundamentado em Doze Passos e Doze Tradições, que, embora inalteráveis, se prestam a reinterpretações. O programa é baseado na abstinência completa e o eixo básico do tratamento é o intercâmbio da experiência etílica dos alcoolistas (Musumeci, 1994).

Em 1953, pessoas que faziam parte dos Alcoólicos Anônimos decidiram morar juntas a fim de se manterem em abstinência e fundaram a Comunidade Terapêutica Synanom, na Califórnia (EUA). A partir desta iniciativa, surgiram outras comunidades terapêuticas que seguiam o mesmo modo de funcionamento da precursora Synanom. No Brasil, as comunidades terapêuticas estão vinculadas, principalmente, às igrejas evangélicas e católicas. Em 1968, na cidade de Goiânia, surge no Brasil a primeira Comunidade Terapêutica denominada Desafio Jovem, oriunda de um movimento religioso evangélico. Em 1978, na cidade de Campinas, foi fundada a Comunidade Terapêutica Senhor Jesus, oriunda de um movimento religioso coordenado pelo Padre Haroldo Rham, missionário americano (Fracasso, 2008).

De acordo com o Glossário de álcool e drogas da SENAD (2010), as comunidades terapêuticas são caracterizadas por um ambiente estruturado onde os indivíduos com transtornos por uso de substâncias psicoativas residem para alcançar a reabilitação e são, em geral, isolados geograficamente. Elas possuem um modelo residencial: uma vez internado, o "residente" deverá comprometer-se com o programa de tratamento da instituição. Os tratamentos podem durar seis, nove ou doze meses, a critério da própria comunidade terapêutica. Os residentes são mantidos em atividades durante o transcorrer do dia, que podem variar entre atividades laborais, terapêuticas e religiosas. As famílias podem realizar visitas à comunidade terapêutica, geralmente, uma vez por mês, em data definida pelo local.

As comunidades terapêuticas pretendem promover mudanças no comportamento dos indivíduos e favorecer sua reinserção na sociedade. Para que isso aconteça, valores como espiritualidade, responsabilidade, solidariedade, amor e honestidade são criados. As comunidades terapêuticas em seu modelo residencial e de funcionamento estão pautadas na premissa de que, diante da impossibilidade de promover mudanças no indivíduo 'dependente químico', é necessário alterar o meio onde ele vive e retirá-lo da situação em que se dá o consumo de drogas. O processo terapêutico preconiza intervenções individuais e sociais com atribuição de funções, direitos e responsabilidades ao 'indivíduo dependente químico', em um ambiente livre de substâncias psicoativas (Sabino \& Cazenave, 2005). 
A partir de tal descrição das comunidades terapêuticas, pode-se relacionar esse modelo com o manicômio, onde a exclusão dos loucos parecia estar justificada pela necessidade de um local 'protegido', com regramentos de horário na rotina dos asilados, que por séculos foram justificados pelas ciências como possibilidade única para os portadores de transtornos mentais.

Segundo Raupp e Milnitisky-Sapiro (2008), o modelo moral que embasa o tratamento na comunidade terapêutica dificulta o desenvolvimento das singularidades e potencialidades dos internos, o que dificulta o alcance de uma recuperação duradoura. Nas comunidades terapêuticas pesquisadas por esta autora, não haviam distinções entre uso, abuso e dependência de substâncias psicoativas, sendo o mesmo programa terapêutico aplicado a todos os residentes das instituições.

No que diz respeito à religião, Raupp e Milnitisky-Sapiro (2008) apontam que a moral cristã imposta como cerne do tratamento configura-se como doutrinação, uma vez que a questão religiosa não é uma resposta adequada às necessidades dos residentes na instituição. Tal imposição acaba limitando o desenvolvimento de recursos para que outras opções de vida possam ser feitas para além da questão religiosa. Sendo assim, o estilo de vida preconizado pela comunidade terapêutica fornece modelos muito rígidos para as características do mundo contemporâneo.

\section{A Articulação entre Moral Religiosa, Disciplina e Biopolítica no Modelo das Comunidades Terapêuticas}

A psiquiatria, de acordo com Foucault (2010), funciona equacionando a vinculação de todo o diagnóstico de loucura à eminência de um perigo. Assim, ela se justifica como uma intervenção autoritária na sociedade, apoiada em um saber científico, funcionando como poder e ciência da higiene pública, pois demonstra ser capaz de perceber perigos onde ninguém ainda pode ver; e se pode percebê-lo, é por que se sustenta em um saber médico. Então, o poder psiquiátrico desloca-se, deixando de inferir sobre o pensamento doente, sobre a capacidade de compreensão do doente, sobre o querer consciente do doente, para investir sobre o que o doente faz, o que ele é capaz de cometer.

As pequenas irregularidades de conduta, que não pertencem, especificamente, à loucura, puderam ser trazidas para o domínio da psiquiatria através do aparecimento da noção de instinto. É com essa noção que poderá se organizar a problemática do anormal na esfera das condutas cotidianas. A função do instinto dentro do jogo de saber-poder é a capacidade de transformar, do ponto de vista da ciência, a ausência de razão de um ato em um mecanismo patológico positivo. No lugar do antigo domínio do delírio e da demência, o instinto é que passa a ocupar um lugar central na psiquiatria (Foucault, 2010).

Sendo assim, o uso de drogas pode ser entendido sob a luz da ausência do controle dos instintos e da ausência de razão. Assim, podemos então dizer que aquele que usa drogas perde o controle de si mesmo e age movido por seus instintos, podendo colocar outras pessoas em risco, além de si mesmo. Com base nesse entendimento, o usuário de drogas pode ser tomado como objeto de intervenção da psiquiatria, devendo ser normalizado. A normalização do usuário de drogas tem se apresentado, especialmente, pela disseminação das instituições denominadas comunidades terapêuticas, que se propõem a produzir sujeitos abstêmios das substâncias psicoativas. 
As políticas sobre drogas que têm a abstinência como objetivo no tratamento são tomadas pela lógica do biopoder. O biopoder pode ser entendido como uma tecnologia que se dirige à multiplicidade dos homens, configurando uma massa global afetada por processos conjuntos da vida. É uma tecnologia que se dirige à vida do homem como um ser vivo (Foucault, 1999).

Nas tecnologias disciplinares, o foco é o corpo individual de cada sujeito em que se produz efeitos subjetivos individualizantes. Nas tecnologias de regulamentação, ou seja, no exercício do biopoder, o alvo é a própria vida. Através do controle da população por parte do Estado, controla-se a relação dos perigos internos à própria sociedade (Scisleski \& Guareschi, 2010).

Com isso, a medicina desempenha o papel de manter a higiene pública. Assim, surgem organismos de coordenação dos tratamentos médicos, centralização de informações e de normalização do saber, assumindo também o aspecto de medicalização da população. Os acidentes, as enfermidades e as anomalias diversas são fenômenos que serão alvo de intervenção não somente por instituições de assistência, mas também por mecanismos mais sutis. Os fenômenos que se tornam pertinentes para intervenção da tecnologia do biopoder são aqueles que adquirem o status de fenômeno de nível de massa: fenômenos coletivos que só aparecem com efeitos econômicos e políticos (Foucault, 2005).

O biopoder se mostra como poder sobre a vida, considerando as políticas da vida biológica e como poder sobre a morte, através do racismo do Estado. Desta forma, trata-se da estatização da vida. O biopoder foi um elemento fundamental para o desenvolvimento do capitalismo na medida em que serviu para assegurar a inserção controlada dos corpos no aparato produtivo e para que os fenômenos populacionais estivessem ajustados aos processos econômicos. Para Foucault, essa forma do poder que é, ao mesmo tempo, individualizante e totalizante é a característica fundamental do poder moderno (Castro, 2009).

O racismo a que Foucault (2005) refere-se não diz respeito ao ódio entre as raças ou uma operação ideológica cujas hostilidades seriam dirigidas a um adversário. O racismo a que o autor refere-se está ligado a tecnologia do poder, está ligado a um mecanismo que permite o exercício do biopoder. O racismo está relacionado ao funcionamento do Estado que é obrigado a utilizar a raça, sua eliminação e purificação, para que ele possa exercer seu poder soberano, que é o poder de fazer morrer. Portanto, o racismo assegura a função de morte na economia do biopoder, seguindo o princípio de que, mediante a morte do outro, fica garantido o fortalecimento biológico da raça da própria pessoa.

A população é a finalidade e o instrumento do governo. Os interesses individuais e os interesses gerais da população constituem o instrumento fundamental do governo. O objetivo do governo é, portanto, melhorar a saúde da população, sua duração de vida, aumentar sua riqueza. Para que isso se efetive, o governo utiliza campanhas que agem diretamente sobre a população e usa técnicas que agem, indiretamente, sobre ela (Foucault, 1978).

Foucault utiliza o termo governamentalidade para se referir ao objeto de estudo das maneiras de governar, ou seja, de conduzir condutas. De acordo com Foucault (1978), a ideia de governamentalidade pode ser assim entendida: primeiramente, por um domínio composto pelo conjunto das instituições, procedimentos, análises, cálculos, táticas que permitem essa forma de exercício de poder sobre a população, tendo como forma central de saber a economia política e como instrumento técnico essencial os dispositivos de segurança, ou seja, a 
biopolítica. O estudo das formas de governamentalidade implica a análise de formas de racionalidade, de procedimentos técnicos, de formas de instrumentalização. Pode ser definida também pela tendência ocidental em que foi preeminente este tipo de poder chamado governo, que se exerce sobre os outros (soberania, disciplina) e que levou ao desenvolvimento de aparelhos específicos de governo e de um conjunto de saberes. As sociedades modernas não são sociedades apenas de disciplinarização, mas também de normalização dos indivíduos e das populações. E, ainda, é o resultado do processo através do qual o Estado de justiça da Idade Média, que se tornou, nos séculos XV e XVI, Estado administrativo, foi pouco a pouco governamentalizado.

Essas estratégias engendram a biopolítica que governa o modo de pensar a saúde da população. As políticas públicas de saúde e de segurança desenham modos de viver, prescrevem práticas e conduzem a condutas no que diz respeito ao uso de drogas e ao tratamento daqueles que são considerados doentes ou dependentes químicos. A biopolítica pela segurança apresenta-se como estratégia atrelada ao poder disciplinar, colocando o usuário ora como um criminoso que deve ser punido ora como um doente que deve ser tratado dentro de uma perspectiva que encontra materialidade no regramento das comunidades terapêuticas. As políticas públicas de saúde, como uma biopolítica - pelo âmbito da legislação, estratégias de segurança e técnicas disciplinares, estabelecem a governamentalidade do usuário de drogas.

As comunidades terapêuticas, por serem instituições fechadas, designadas a dispensar tratamento para usuários através da segregação social, com normas rígidas de funcionamento e controle sobre a vida dos indivíduos, remetem à memória de antigas instituições, como o leprosário e o manicômio. Essas, presentes no mundo ocidental desde a Idade Média, parecem reeditar-se em instituições que, ainda hoje, estão presentes nas diversas sociedades. As comunidades terapêuticas, assim, parecem ser como reedição deste modelo, agora sob a justificativa da dependência química como a doença que deve ser tratada através do isolamento. As práticas destas instituições, desde a Idade Média com as dos leprosários e hospícios, constituíram modos de tratamento e sujeitos, que alicerçou saberes que a Reforma Psiquiátrica contestou, mas que ainda encontram condição de existência por estarem arraigados aos saberes de disciplinas como a medicina, a psicologia, e o direito.

Os espaços fechados de tratamento para pessoas com problemas com o uso de drogas como as comunidades terapêuticas podem ser consideradas como espaços onde se estabelecem relações de dominação daquele que exerce um poder dito terapêutico sobre um sujeito desprovido de seus direitos, "[...] abandonado à arbitrariedade institucional" (Alarcon, Belmonte, \& Jorge, 2012, p. 73). A institucionalização é o artifício para práticas desumanizadas, tornando-os sujeitos desprezíveis. Por isso, as críticas feitas aos leprosários e depois aos hospitais psiquiátricos podem se estender à instituições como as comunidades terapêuticas que nasceram à sombra da racionalidade manicomial, pois entendem saúde pela simplificação unicausal e institucionalizam o sujeito (Alarcon et al., 2012).

A construção de políticas de saúde para usuários de drogas centradas no hospital psiquiátrico demarca a interferência significativa do Direito Penal sobre os procedimentos clínicos, assim como a aproximação entre práticas jurídicas e práticas médicas. É dentro deste jogo de poder que o usuário de drogas se vê ora perante o poder da criminologia, ora diante do 
poder da psiquiatria, ora encarcerado na prisão, ora internado no hospício. Esse conjunto institucional, de acordo com Foucault (2010), está voltado para o indivíduo que não é nem exatamente doente nem propriamente criminoso, mas sim para o indivíduo, eventualmente, perigoso, nesse caso, os usuários de drogas. Porém, atualmente, não é só dentro das prisões e dos hospícios que os usuários de drogas estão confinados. As Comunidades Terapêuticas e Fazendas Terapêuticas trazem, além da disciplina, outro elemento que a complementa: a moral religiosa (Passos \& Souza, 2011).

A justiça, a psiquiatria e a moral cristã compõem uma rede de instituições que tem como objetivo comum e único a abstinência, ou seja, a conformação de sujeitos que não tenham problema com o uso de drogas. Sujeitos esses que possam estar inseridos social e economicamente, fazendo 'girar a roda' de produção e consumo de nossa sociedade. A moral religiosa associa o prazer ao mal - associa o prazer da carne ao uso de drogas, que, historicamente, é objeto de intervenção do poder pastoral, que, atualmente, se alia ao poder disciplinar. A problematização moral do uso de drogas assenta-se sobre um conjunto de regras morais cristã, que situou o prazer sob o signo do mal e da morte (Passos \& Souza, 2011).

Segundo Siqueira (2010), existem três espaços destinados aos usuários de drogas, que são: cadeia, igreja e hospitais psiquiátricos. Lugares escolhidos a fim de desempenharem a função de 'controle da sociedade' por meio de leis que estão pautadas nos princípios morais. Assim, há uma produção de sujeitos com identidades padronizadas em que a singularidade e as diferenças não são respeitadas. Esses espaços oferecem a garantia de manutenção da invisibilidade dessas diferenças.

As comunidades terapêuticas, em sua estrutura e funcionamento, organizam-se e articulam-se como cadeia, igreja e hospital psiquiátrico. As comunidades terapêuticas não podem ser caracterizadas unicamente nem como cadeia, nem como igreja, nem como hospital psiquiátrico, mas, justamente, é na articulação do funcionamento destas três instituições que elas encontram sua especificidade - que mais se aproxima dessas três instituições do que dos serviços que preconizam os princípios do SUS. Na cadeia, temos, principalmente, o caráter fechado, a impossibilidade do indivíduo preso circular na cidade, além do sentido de que o encarceramento é uma medida necessária para aquele que comete um crime. No caso dos usuários de drogas, seu crime (que, nesse caso, é moral) foi justamente o uso de substâncias ilícitas, que, portanto, será combatido com o encarceramento em um local para o tratamento da drogadição, a fim de devolver para a sociedade, um indivíduo abstêmio que consiga se inserir à lógica da moral. O método utilizado para recuperar moralmente este indivíduo para torná-lo produtivo se dá, principalmente, pela questão religiosa. É neste ponto que vemos como a comunidade terapêutica toma as características de instituição religiosa.

Desta forma, e conforme Valderrutén (2008), as comunidades terapêuticas em sua natureza social que segue a lógica do internamento são uma das tantas formas históricas contemporâneas do jogo de exclusão dos seres humanos, em que eclodem rituais de segregação e purificação por meio das práticas terapêuticas e dos discursos morais. As comunidades terapêuticas possuem um "híbrido" de concepções morais e éticas, conjugando "velhas" e "novas" visões e valores acerca do indivíduo e da sociedade. 


\section{Projetos Terapêuticos de Atenção aos Usuários de Álcool e Outras Drogas das Comunidades Terapêuticas: A Análise de Quatro Propostas de Tratamento}

A fim de visibilizar como as comunidades terapêuticas se organizam para receber e tratar os usuários de substâncias psicoativas, através de pactuação com a atual política de drogas no país, apresentamos os projetos de quatro comunidades terapêuticas. Dessa forma, apontamos como se constitui o entrelaçamento entre o poder psiquiátrico, a disciplina e a punição, dessas instituições a partir do conteúdo disponível em suas páginas na internet. Com a análise da proposta terapêutica dessas comunidades, discutimos os efeitos do modelo terapêutico sustentado a partir da moral do trabalho, da família e da religião nos modos de subjetivação do sujeito usuário de drogas. As instituições pesquisadas são as seguintes: Comunidade Terapêutica Fazenda Renascer² (2012), Novo Hamburgo, RS; Centro de Reintegração Social Aprendendo a Viver ${ }^{3}$ (2013), Sapiranga, RS; Comunidade Terapêutica Ferrabraz ${ }^{4}$ (2013), Sapiranga, RS; e Fazenda do Senhor Jesus ${ }^{5}$ (2013), Viamão, RS. Todas possuem página na internet e disponibilizam, publicamente, os projetos terapêuticos de tratamento para usuários de drogas bem como demais informações sobre a estrutura institucional e seu funcionamento. A escolha por estas quatro comunidades terapêuticas deu-se pela riqueza e detalhamento das informações contidas em seus sítios.

A Comunidade Terapêutica Fazenda Renascer é direcionada para pessoas do sexo masculino na faixa dos 16 aos 60 anos, tendo capacidade para 60 residentes na instituição. Sua filosofia de trabalho está baseada em uma declaração feita pelo jornalista Richard Beauvais após sua internação na Comunidade Terapêutica Daytop Village nos EUA, que segue a premissa dos Alcoólicos Anônimos.

A orientação do tratamento na Fazenda Renascer são os Doze Passos de Recuperação do AA. O programa terapêutico conta com três princípios básicos: espiritualidade, disciplina e trabalho e possui um cronograma para um ano de tratamento. A disciplina é promovida como um meio para dominar os impulsos, uma vez que, no entendimento da comunidade terapêutica, o dependente químico tem aversão à regras e normas e, por isso, foge dos padrões estabelecidos pela sociedade. Portanto, a comunidade terapêutica tem a pretensão de produzir sujeitos aptos aos padrões sociais, que insiram normativamente aos ditames da sociedade. O público da comunidade terapêutica são os sujeitos 'desajustados'.

Essa instituição considera que a dependência química é uma doença biopsicossocial e espiritual e, por esse motivo, o usuário de drogas precisa de ajuda externa para redirecionar sua vida, promovendo uma transformação através da mudança de seus valores e do seu estilo de vida. Em outros termos, no tratamento da comunidade terapêutica, opera-se uma constituição de novos valores através de práticas ditas 'espirituais' e, portanto, valores advindos de preceitos religiosos. Não há informações sobre quais profissionais atuam no local, mas são citados os seguintes recursos de tratamento: assistência psicológica (individual e em grupo), esporte e lazer, educação física, tai chi chuan, karatê, academia e prática de informática.

\footnotetext{
${ }^{2}$ http://www.fazendarenascer.org.br/novo/

${ }^{3}$ http://www.aprendendoaviver.com/

${ }^{4}$ http://www.comunidadeferrabraz.com.br/

${ }^{5}$ http://www.pactopoa.com.br/
} 
O Centro de Reintegração Social Aprendendo a Viver está localizado em um centro urbano, seguindo o modelo residencial. A instituição refere que o tratamento é personalizado, sem crédulo religioso, mas espiritual, e destaca que não tem 'trabalhos forçados'. O tratamento está dividido em três etapas: desintoxicação, tratamento de dependência química e pós-tratamento. Nestas etapas, o residente deve identificar sua doença, aceitar sua condição de pessoa doente que necessita de tratamento, formular uma programação pessoal de reabilitação, conhecer o programa de doze passos do AA e preparar-se para a sua reinserção social. Ainda que essa comunidade terapêutica afirme não ter crédulo religioso, ao impor o programa dos doze passos do AA, fica subentendido que o usuário deva, no mínimo, acreditar em um 'deus' ou em um 'poder superior'. Com isso, podemos inferir que há uma conformação 'espiritual' no tratamento, uma vez que, para tomar o método do AA como diretriz, o sujeito deve reconhecer como verdade as premissas dos doze passos.

O pós-tratamento consiste em acompanhamento ambulatorial e participação em reuniões semanais de grupos de AA ou NA. O Centro possui uma equipe técnica formada por médico psiquiatra, médico clínico geral, psicóloga, assistente social e técnicos de enfermagem e oferece como atividades: terapia individual, terapia em grupo, terapia familiar, atendimento psiquiátrico, clínico e psicológico, oficinas terapêuticas, espiritualidade, atividades lúdicas e de lazer, grupos de AA e NA.

A Comunidade Terapêutica Ferrabraz tem seu tratamento baseado na programação dos Doze Passos do AA, empregando métodos que decorrem da postura filosófica que têm como base o tripé: oração, trabalho e disciplina. A oração diz respeito ao desenvolvimento da espiritualidade, que é considerada o alicerce fundamental para a recuperação. O trabalho compreende as atividades de manutenção e funcionamento da instituição, resgatando o sentido e o gosto pelo trabalho. A disciplina está associada ao cumprimento rigoroso dos horários, compromissos, apresentação pessoal, tarefas, comunicação adequada e vocabulário. Dentre as três premissas de tratamento, a oração e o desenvolvimento da espiritualidade são considerados o alicerce para o tratamento. O desenvolvimento da espiritualidade diz respeito à construção de valores de ordem religiosa, inexistentes antes da internação, e que, sendo instituídos pelos sujeitos, os modificam, para assim obterem a recuperação.

O funcionamento da instituição Ferrabraz constitui-se em sistema aberto com regime de residência em ambiente protegido. Esta comunidade terapêutica afirma que o dependente químico só tem condições de se manter abstêmio após um período de tempo afastado de seu meio original. O programa de tratamento é desenvolvido em nove meses, divididos em três etapas. A primeir trimestre é etapa de adaptação e desintoxicação. A segunda etapa, no segundo trimestre, é denominada conscientização. Na última fase, a da ressocialização, são permitidas visitas às famílias que duram uma semana. A instituição oferece atendimento com psicólogos, assistentes sociais e psiquiatras. A metodologia empregada consiste em diversas técnicas terapêuticas grupais: grupo dos doze passos dos Alcoólicos Anônimos, grupo de amor exigente, grupo de sentimento, grupo de auto-ajuda, grupo de socioterapia, grupo de espiritualidade, grupo de laborterapia, grupo psicológico, grupo de terapia racional emotiva.

A Comunidade Terapêutica Fazenda do Senhor Jesus tem seu funcionamento estruturado a partir de valores físicos, éticos, morais, intelectuais e espirituais e entende que os valores de uma comunidade terapêutica estão para ela assim como sangue está para a vida. Os valores estão designados conforme os princípios fundamentais do código de ética da Federação 
Brasileira de Comunidades Terapêuticas (FEBRACT) e são definidos como: respeito à dignidade humana; permanência e aceitação do programa de forma livre e voluntária; permanência assegurada em ambiente livre de drogas, sexo e violência; amor responsável; honestidade; solidariedade; busca de um sentido de vida.

A instituição determina um tratamento com duração de 9 meses e seu público é composto por pessoas do sexo masculino. Existem cerca de 96 vagas na comunidade terapêutica. Para o ingresso, é necessário que a pessoa se submeta a um processo de triagem e avaliação. Neste processo, inclui-se avaliação psicológica e avaliação socioeconômica, com a necessidade de acompanhamento de um responsável pela internação. A equipe de trabalho é formada por dependentes químicos em recuperação com estágio em comunidade terapêutica. Com isso, a instituição visa a articulação entre a experiência de vida dos dependentes químicos com a capacitação técnica de profissionais, que são voluntários, da área da toxicologia, psicologia, assistência social, saúde e administração. No que concerne às atividades terapêuticas, a comunidade terapêutica conta com: laborterapia, exercício de rígida disciplina individual e coletiva, desenvolvimento de vida comunitária, estudo e vivência dos doze passos do AA, estudo e vivência dos doze princípios do Amor Exigente, reuniões de grupo com várias destinações, atividades esportivas e lúdicas e oração sob todas as formas.

A conformação de projetos terapêuticos para o tratamento pelo viés da disciplina, da espiritualidade e do trabalho operam sobre os sujeitos através de técnicas de cuidado de si, de práticas disciplinares e punitivas, aliançadas com os saberes da psicologia e do cristianismo valendo-se do mecanismo da punição para conseguir as metas do tratamento. Três eixos norteadores para a constituição de sujeitos socialmente ajustados, inseridos moralmente na instituição religiosa, no mercado de produção-consumo, nas instituições de ensino, na vida política-econômica. Eixos que com caráter punitivo, delegam os sujeitos a cumprirem os regramentos institucionais; sob pena de práticas físicas para a regulação e a constituição da volta um corpo saudável e produtivo.

Os Doze Passos

1. Admitimos que éramos impotentes perante o álcool- que tínhamos perdido o domínio sobre nossas vidas.

2. Viemos a acreditar que um Poder Superior a nós mesmos poderia devolver-nos à sanidade.

3. Decidimos entregar nossa vontade e nossa vida aos cuidados de Deus, na forma em que $\mathrm{O}$ concebíamos.

4. Fizemos minucioso e destemido inventário moral de nós mesmos.

5. Admitimos, perante Deus, perante nós mesmos e perante outro ser humano, a natureza exata de nossas falhas.

6. Prontificamo-nos inteiramente a deixar que Deus removesse todos esses defeitos de caráter.

7. Humildemente rogamos a Ele que nos livrasse de nossas imperfeições.

8. Fizemos uma relação de todas as pessoas que tínhamos prejudicado e nos dispusemos a reparar os danos a elas causados.

9. Fizemos reparações diretas dos danos causados a tais pessoas, sempre que possível, salvo quando fazê-lo significasse prejudicá-las ou a outrem. 
10. Continuamos fazendo o inventário pessoal e, quando estávamos errados, nós o admitíamos prontamente.

11. Procuramos, através da prece e da meditação, melhorar nosso contato consciente com Deus, na forma em que O concebíamos, rogando apenas o conhecimento de Sua vontade em relação a nós e forças para realizar essa vontade.

12. Tendo experimentado um despertar espiritual, graças a esses Passos, procuramos transmitir esta mensagem aos alcoólicos e praticar estes princípios em todas as nossas atividades (Vivência, 2011, p. 1).

\section{Aspectos Punitivos do Tratamento nas Comunidades Terapêuticas: A Conformação do Uso de Drogas como Dano Social}

Em "A sociedade punitiva", Foucault (1997) afirma que, a partir do século XVIII, a nossa sociedade passou a enclausurar, trazendo a prisão como recurso para a punição daqueles que infringem a lei. Paralelo à sua construção, as prisões foram objeto de críticas alijadas em princípios fundamentais e nos desfuncionamentos possíveis que a prisão poderia trazer para o sistema penal e para a sociedade em geral. Sendo assim, a prisão foi apontada como um instrumento que fabrica aqueles que serão encarcerados. Essa crítica hoje é dada como fatalidade (Foucault, 1997).

Os reformadores penais do século XVIII definiram, a partir do interesse da sociedade, a noção de crime e a necessidade de punição. Com isso, tem-se como consequência, o estabelecimento do castigo para o perigo ou dano causado à sociedade e não à falta em si. O papel da pena é voltado a impedir que o crime recomece, colocando o culpado fora da possibilidade de causar prejuízo. Com os princípios destes reformadores, outros modelos punitivos foram possíveis: o primeiro deles articulado à infâmia, outro associado a lei do talião e o último caracterizado pela escravização em benefício da sociedade (Foucault, 1997).

A infâmia diz respeito aos efeitos da opinião pública que incidem sobre o sujeito criminoso como uma reação espontânea da própria sociedade. É uma pena que se ajusta ao crime sem a necessidade de passar pelo código penal e pelo tribunal. O modelo do talião impõe um castigo equivalente à natureza do crime cometido e, apesar de nunca ter sido proposto de forma especificada, permitiu definir modos de punição. Esse modelo pode ser pensado sob a forma de um talião moral que pune o crime sem a intenção de reverter seu efeito, mas incidindo sobre os vícios que o motivaram. A escravização é estabelecida em intensidade e duração conforme o prejuízo causado. Foucault (1997), fazendo referência a escritos de Brissot (sem referência da obra) afirma: "O que substitui à pena de morte? A escravidão que põe o culpado fora de condição de causar prejuízo à sociedade; trabalho que o torna útil; a dor longa e permanente que amedronta aqueles que ficariam tentados a imitá-la" (p. 35).

Na análise dos Doze Passos dos Alcoólicos Anônimos, tomados como metodologia de tratamento nos projetos terapêuticos estudados, destacamos os seguintes itens como prescrições disciplinares e punitivas no tratamento das comunidades terapêuticas: os passos 6 (Prontificamo-nos inteiramente a deixar que Deus removesse todos esses defeitos de caráter), 7 (Humildemente rogamos a Ele que nos livrasse de nossas imperfeições), 8 (Fizemos uma relação de todas as pessoas que tínhamos prejudicado e nos dispusemos a reparar os danos a elas causados) e 9 (Fizemos reparações diretas dos danos causados a tais pessoas, 
sempre que possível, salvo quando fazê-lo significasse prejudicá-las ou a outrem), trazem em sua discursividade os aspectos punitivos consequentes aos que fizeram uso de drogas. Nos passos 6 e 7, o uso de drogas é apontado como um defeito de caráter e imperfeição que necessitam ser removidos por 'Deus'. Essa remoção, no âmbito desta pesquisa, pode ser entendida como o sentido da comunidade terapêutica se estabelecer como uma instituição fechada, que enclausura o sujeito usuário de drogas. Enclausuramento para a remoção dos defeitos de caráter para que o sujeito possa retornar à sociedade, em que a comunidade terapêutica opera como prisão em sua característica punitiva e segregadora. Nesse caso, as comunidades terapêuticas funcionam como recurso de enclausuramento daqueles que são considerados ameaças para a ordem social, que vêm sendo apontados pela mídia - como já vimos anteriormente - como potenciais criminosos. Se, no âmbito da justiça e da segurança pública, os usuários de drogas não são necessariamente enquadrados como criminosos, um outro "enquadre" se constitui através do tratamento em instituições de longa permanência como as comunidades terapêuticas.

Os passos 8 e 9 determinam que o uso de drogas produziu danos e prejuízos que devem ser reparados. Essas prescrições incidem sobre o uso de drogas enquanto dano social, ou seja, colocam o usuário de drogas enquanto alguém que, com uma prática individual de consumo de substâncias, desestabiliza a ordem social. Nesse entendimento, o sujeito usuário de drogas, em seu caráter improdutivo do ponto de vista da lógica neoliberal, deve reaver-se com a sociedade, retornando como um sujeito dotado de arrependimento por seus "erros" e que, por tê-los cometido, se compromete com a reparação através de uma conduta de abstinência.

A partir do exposto acima, podemos entender do ponto de vista dos ensinamentos de Foucault, as atuais medidas governamentais para o tratamento de usuários de drogas como um exercício de biopoder. Diante do aumento da população usuária de drogas, do uso de drogas como um problema social apontado como produtor de violência nas cidades, do uso de drogas como impossibilidade de inserção na lógica de produção-consumo imposta pela sociedade, o consumo de drogas - especificamente o crack - foi tomado como ameaça à ordem social e econômica e como fenômeno coletivo, passou a ser alvo de investimento estatal. O Plano Integrado de Enfrentamento ao Crack e a campanha "Crack é possível vencer" se apresentam, então, como um investimento de biopoder sobre a população usuária de crack para que essa seja potencializada como vida produtiva. Esse investimento materializa-se como inserção das comunidades terapêuticas na rede pública de saúde.

Sob esse entendimento, então, as comunidades terapêuticas se inserem como estratégia disciplinar e biopolítica através de um isolamento, que, ao mesmo tempo que produz a segregação dos sujeitos usuários de drogas, produz também uma conformação deles de modo que retornem ao seu andar da vida devidamente curados da necessidade de consumir drogas para que possam estabelecer outras relações de consumo, atravessadas pela lógica neoliberal.

A internação em comunidade terapêutica pode ser entendida como uma medida punitiva. O tratamento que incide sobre o "vício" da droga, pretende a conformação de sujeitos que sejam produtivos economicamente no mercado formal de trabalho e que não venham a se tornar sujeitos inseridos no mercado do tráfico de drogas. A característica segregadora das comunidades terapêuticas encontra condição de existência e permanência em nosso tempo por conta do fenômeno coletivo do pânico moral em relação ao consumo e ao tráfico de drogas. 


\section{Considerações Finais}

Os doze passos das comunidades terapêuticas forjam o tratamento a partir de uma concepção proibicionista e, ao mesmo tempo, afirmam a abstinência como único modo de "lidar" com as substâncias, positivando técnicas que conformam como o sujeito se constituirá e se cuidará. O sujeito produzido por estas técnicas está 'alheio' de si mesmo, já que é um poder superior que o ajudará a alcançar o objetivo da abstinência. Esse assujeitamento, essas práticas conformam e produzem, como vimos, os modos como os usuários de drogas ao serem investidos por essa metodologia, por essas comunidades terapêuticas, acabam por se relacionar consigo e com o mundo conforme as prescrições moralizantes destas instituições.

Conciliadas as duas lógicas - proibicionismo e Redução de Danos - uma outra política brasileira se constituiu. O Ministério da Saúde, além de financiar o credenciamento dos leitos em comunidades terapêuticas, criou um serviço público de acolhimento com caráter residencial para usuários de drogas, como vistas a manutenção da abstinência, conforme a apresentação da campanha "Crack é possível vencer", como vimos anteriormente. As comunidades terapêuticas, que pareciam entes externos a rede de saúde, que pareciam ser serviços inconjugáveis à rede estabelecida após a Reforma Psiquiátrica, passaram a ocupar o papel principal dentro da "nova política".

Portanto, o contexto que precede a criação de uma política de saúde mental baseada em preceitos antimanicomiais é configurado por uma lógica proibicionista e moralista, em que nenhum consumo de drogas pode ser visto como possível. A abstinência, sendo assim, era tomada como a única medida cabível. Como meta, a redução da demanda possibilitou a entrada do poderio militar estadunidense em diversos territórios do globo terrestre, indicando que essa política de guerra às drogas serve aos interesses econômicos e mercadológicos de um país que é uma super potência e que trabalha em prol de sua hegemonia mundial.

A metodologia de tratamento nas comunidades terapêuticas, em suas práticas punitivas, busca forjar sujeitos economicamente produtivos, inserindo-os novamente na lógica de consumo do neoliberalismo. Assim, além dos efeitos legislativos e jurídicos desta inserção, as comunidades terapêuticas conformam modos de subjetivação.

\section{Referências}

Alarcon, S. (2012). A síndrome de Elêusis: Considerações sobre as políticas públicas no campo de atenção ao usuário de álcool e outras drogas. In S. Alarcon, \& M. A. S. Jorge (Orgs.), Álcool e outras drogas: Diálogos sobre um mal-estar contemporâneo. Rio de Janeiro: Fiocruz.

Alarcon, S., Belmonte, P., \& Jorge, M. (2012). O campo de atenção ao dependente químico. In S. Alarcon, \& M. A. S. Jorge (Orgs.), Álcool e outras drogas: Diálogos sobre um mal-estar contemporâneo (pp. 63-81). Rio de Janeiro: Fiocruz.

Brasil. (2010). Decreto n. 7.179. Diário Oficial da União, Brasília, DF. Disponível em http:// www2.camara.leg.br/legin/fed/decret/2010/decreto-7179-20-maio-2010-606392normaatualizada-pe.html

Bucher, R., \& Oliveira, S. R. M. (1994). O discurso do "combate às drogas" e suas ideologias. Revista de Saúde Pública, 28(2), 137-145. Disponível em http://www.scielo.br/scielo. php?script=sci_arttext\&pid=S0034-89101994000200008\&lng=pt\&nrm=iso 
CASTRO, E. (2009). Vocabulário de Foucault: Um percurso pelos seus temas, conceitos e autores. Belo Horizonte: Autêntica.

Crack, é possível vencer. (2011). Disponível em https://www.cnm.org.br/cms/biblioteca_ antiga/ET\%20Vol\%207\%20-\%2019.\%20Crack,\%20\%C3\%A9\%20poss\%C3\%ADvel\%20 vencer.pdf

Delmanto, J., \& Magri, M. (2011). O enfoque na mudança de mentalidade como arma para suplantar o proibicionismo. In Conselho Regional de Psicologia da 6 região (Org.), Álcool e outras drogas. São Paulo: CRPRS.

Foucault, M. (1978). Microfísica do poder. Rio de Janeiro: Graal.

Foucault, M. (1997). Resumo dos cursos do Collège de France (1970-1982). Rio de Janeiro: Jorge Zahar.

Foucault, M. (1999). História da loucura (6a ed.). São Paulo: Perspectiva.

Foucault, M. (2005). Em defesa da sociedade: Curso dado no Collége de France (1975-1976). São Paulo: Martins Fontes.

Foucault, M. (2010). Os anormais. São Paulo: WMF/Martins Fontes.

Fracasso, L. (2008). Comunidade terapêutica: Uma abordagem psicossocial. Encontro Interdisciplinar: Dependência Química, Saúde e Responsabilidade Social - Educando e Transformando Através da Educação Física. Disponível em http://www.fef.unicamp.br/ bibli/Encontrointerdisciplinar/Texto\%202\%20Laura.pdf

Glossário de Álcool e Drogas. (2010). Brasília: Secretaria Nacional de Políticas sobre Drogas. Disponível em http://www.campinas.sp.gov.br/governo/assistencia-social-segurancaalimentar/prevencao-as-drogas/glossario.pdf

Jones, M. (1972). A comunidade terapêutica. Petrópolis, RJ: Vozes.

Musumeci, B. (1994). O consumo de álcool no país. In A. Zaluar (Org.), Drogas e cidadania: Repressão ou redução de riscos. São Paulo: Brasiliense.

Passos, E. H., \& Souza, T.P. (2011). Redução de danos e saúde pública: Construções alternativas à política global de "guerra às drogas". Psicologia \& Sociedade, 23(2), 154-162. Disponível em http://www.scielo.br/scielo.php?script=sci_arttext\&pid=S0102-71822011000100017\&ln $\mathrm{g}=\mathrm{pt} \& \mathrm{nrm}=\mathrm{iso}$

Raupp, L. M., \& Milnitisky-Sapiro, C. (2008). A "reeducação" de adolescentes em uma comunidade terapêutica: O tratamento da drogadição em uma instituição religiosa. Psicologia: Teoria e Pesquisa, 24(3), 361-368. Disponível em http://www.scielo.br/scielo. php?script=sci_arttext\&pid=S0102-37722008000300013\&lng=en\&nrm=iso

Sabino, N. D. M., \& Cazenave, S. O. (2005). Comunidades terapêuticas como forma de tratamento para a dependência de substâncias psicoativas. Revista Estudos de Psicologia, 22(2), 167-174. Disponível em http://www.scielo.br/pdf/estpsi/v22n2/v22n2a06.pdf

Scisleski, A., \& Guareschi, N. M. F. (2010). Governando a vida: (Pro)vocações para a psicologia. In N. M. F. Guareschi et al. (Orgs.), Psicologia, formação, políticas e produção em saúde. Porto Alegre: EDIPUCRS.

Siqueira, D. (2010). Construindo a descriminalização... In L. M. B. Santos (Org.), Outras palavras sobre o cuidado de pessoas que usam drogas (pp. 65-69). Porto Alegre: Ideograf/ Conselho Regional de Psicologia do Rio Grande do Sul. Disponível em http://www.crprs. org.br/upload/edicao/arquivo48.pdf 
Valderrutén,M.delC.C.(2008). Entre "teoterapias"y "laicoterapias": comunidadesterapéuticas enColombiaymodelosdesujetossociales.Psicologia \&Sociedade,20(1),80-90. Disponívelem http://www.scielo.br/scielo.php?script=sci_arttext\&pid=S0102-71822008000100009\&ln $\mathrm{g}=\mathrm{pt} \& \mathrm{nrm}=\mathrm{iso}$

Veiga-Neto, A. (2007). Foucault e a educação (2a ed.). Belo Horizonte: Autêntica.

Vivência. (2011). Revista Brasileira de Alcoólicos Anônimos, 26(1).

Recebido: 04/08/2017

última revisão: 04/09/2017

Aceite final: 11/12/2017

\section{Sobre as autoras:}

Luciana Barcellos Fossi- Psicóloga, Mestre em Psicologia Social e Institucional pela Universidade Federal do Rio Grande do Sul. Docente do Curso de Psicologia da Univates. E-mail: Iubfossi@hotmail.com

Neuza Maria de Fátima Guareschi- Psicóloga, Doutora em Educação pela Universidade de Wisconsin - Madison. Mestre em Psicologia Social e da Personalidade pela Pontifícia Universidade Católica do Rio Grande do Sul. Professora Adjunta da Universidade Federal do Rio Grande do Sul. E-mail: nmguares@gmail.com 